\title{
FÉ CRISTÃ, CONHECIMENTO E EDUCAÇÃO: PAIDÉIA AO ALCANCE DE TODOS
}

\section{Christian faith, knowledge and education: the paidéia to the reach of all.}

Renato Gross ${ }^{1}$

\section{Resumo}

O presente trabalho, resultado de pesquisa histórico-bibliográfica, procura apresentar o itinerário percorrido no processo de apropriação pelo cristianismo do conceito grego de Paidéia. A nascente igreja cristã, ao modificar a concepção pagã de mundo, desde o seu início, procurou unir processos do ensino da sua mensagem com a busca do conhecimento. A fundamentação histórica deste processo é encontrada na tradição judaica do estudo da Toráh. A Paidéia Christi por sua vez é explicitada no Logos joanino, nas epístolas paulinas, na patrística e na teorização medieval. Cristo, como pedagogo da humanidade (cf. Clemente de Alexandria) ao atrair todos a si, não fazendo distinção nem de classe nem de pessoa, contribui para que grandes parcelas da população do mundo da época, durante e ao fim do processo de catecumenato, tivessem aberto para si o caminho do conhecimento. E este fato não se restringiu apenas à conversão, mas contribuiu também para incluir no processo educativo cristão pessoas que de outra forma dele ficariam excluídas. Deu assim a sua contribuição à evolução das idéias pedagógicas, que séculos depois culminou no ideário da modemidade e seu projeto educativo.

Palavras-chave: Filosofia; Educação; Cristianismo.

1 Doutor em Educação, Universidade de Campinas, Unicamp. Professor da Universidade Tuiuti do Paraná

Endereço para contato: Rua Sydnei Antônio Rangel Santos, 238 - Sto. Inácio - 82010-330, Curitiba.

E-mail: grossrenato@yahoo.com.br 


\section{Summary}

The present work, result of historical-bibliographical research, intend to present the itinerary covered in the process of appropriation by the Christianity of the Greek concept of Paidéia. The rising Christian church, when modifying the heathen conception of world, since its beginning, looked for to join processes of the education of its message with the search of the knowledge. The historical base of this process is in the Jewish tradition of the study of the Toráh. The Paidéia Christi, in turn is expressed in the Et. John's Logos, in the St.Paul's epistles, the patristic and the medieval theorization. Christ, as the humanity pedagogue (cf. Clement of Alexandria) when attracting all to himself, not making distinction nor social classes nor persons, contributes so that great parcels of the population of the world of that time, during and to the end of the cathecumenathic process, had opened for themselves the way of the knowledge. And this fact, was not restricted only to the conversion, but it also contributed to include in the Christian educative process, people who otherwise would be excluded. It gave thus, its contribution to the evolution of the pedagogical ideas, that centuries later culminated in the ideals of modernity and its educative project.

Keywords: Philosophy; Education; Christianity

\section{Introdução}

Vinte séculos atrás, numa remota e periférica província romana, à semelhança do que ocorrera nos primórdios micênicos da Grécia arcaica, começa a surgir um novo e radical sistema de idéias, destinado a alterar os rumos da História e a contribuir decisivamente com a cultura ocidental: o cristianismo. A religião cristã, sob um início tímido na Palestina, sob a implacável perseguição romana nos seus dois primeiros séculos, rapidamente expandiu-se. Transformou o mundo clássico sob o influxo de sua mensagem e, após a conversão de Constantino, não encontrou mais obstáculos nem barreiras para a sua expansão.

A passagem do paganismo para o cristianismo sempre tem intrigado os historiadores da Antigüidade, pela forma, profundidade e rapidez como ocorreu. Durkheim indica que:

O que caracterizava essencialmente a Igreja e a moral que trazia para 0 mundo, era o desprezo pelas alegrias deste mundo, pelo luxo material e moral; propunha substituir a alegria de viver pelas alegrias mais severas da renúncia. Nada mais natural que semelhante doutrina tivesse conseguido agradar ao Império Romano, cansado de longos séculos de hipercivilização. Só traduzia e consagrava o sentimento de saciedade e desgosto que, havia já muito tempo, trabalhava a sociedade romana e que o epicurismo e o estoicismo já haviam expressado à sua maneira. Tinham-se esgotado todos 
os prazeres a serem proporcionados pelos refinamentos da cultura; havia, pois, uma grande disposição para acolher, como sendo uma salvação, uma religião que vinha revelar aos homens uma fonte toda diferente de felicidade (1995, p.26).

Isto para os romanos. E para os povos bárbaros, povos jovens, destituídos de séculos civilizatórios, acostumados ao nomadismo, a uma vida de privações, de pobreza, de rudeza? O próprio Durkheim responde: "Era, por excelência, a religião dos pequenos, dos modestos, dos pobres, material e espiritualmente pobres. Exaltava as virtudes da humildade, da mediocridade, tanto intelectual como material. Apregoava a simplicidade dos corações e da inteligência" (Ibid, p. 27).

Ao final do Império Romano, com a conversão dos bárbaros e consolidação da Igreja Católica, as coisas chegaram a um ponto que Gibbon (1989, p. 229) resume em duas expressões plenas de significado: Igreja perseguida, Igreja triunfante. E ele próprio tentando encontrar respostas para o triunfo tão rápido do cristianismo, enumera cinco fatores que favoreceram e assistiram tal "triunfo":

- $\quad$ inflexível zelo e a intolerância dos cristãos - derivada, em verdade, da religião judaica mas purificada do espírito acanhado e anti-social que, em vez de atrair, dissuadia os gentios de abraçarem a lei de Moisés;

- a doutrina de uma vida futura, valorizada por toda e qualquer circunstância ocasional que pudesse dar peso e eficácia a essa importante verdade;

- os poderes miraculosos atribuídos à Igreja primitiva;

- a pura e austera moralidade dos cristãos;

- a união e a disciplina da república cristã, que formou aos poucos um Estado independente que se desenvolveu no coração do império romano (GIBBON, 1989, p.195).

Mas cedo no cristianismo evidenciou-se a necessidade de se estabelecer nexos entre fé cristã, conhecimento e educação, dentro do contexto de crer e aprender, e da integração da Fé com o ensino. Contrapondo-se à Paidéia anterior, determinista, seletiva e elitista, surge agora a Paidéia cristã Paidéia Christi, a todos aqueles que a ela estivessem dispostos a aderir. $\mathrm{Na}$ história das idéias pedagógicas, este é o momento decisivo, pois indica uma virada de perspectiva educacional. Para o cristianismo não havia mais patrísticos, nem bárbaros, escravos ou libertos. Nem judeus ou gentios, já que 0 convite "Vinde a Mim" era totalmente inclusivo. A concepção educacional subverteu-se, pois 
A ideologia determinista do dom, como posse inata, e das potencialidades restritas aos estamentos antigos, foi duramente abalada pela 'boa-nova' de 'todos os que n'Ele crerem, poderão ser salvos', interpretando a máxima cristã 'Ite, eunte omnes docete', isto é, 'Ide, ensinai a todos os povos'. Não podemos deixar de afirmar que o projeto pedagógico da expansão cristã partia de uma filosofia humanista e igualitária, sustentando, pela primeira vez, que todos poderiam ter acesso ao saber, conquanto todos poderiam aprender e, conseqüentemente, almejar a 'salvação' (NUNES, 2003, p.81).

Nunes clarifica nesta sua citação, o caráter fortemente inclusivo do projeto pedagógico que surgia concomitante com o cristianismo. Sua fundamentação era igualitária e antropocêntrica, pois abrangia a todos e todas que, ao ouvir as "boas novas", estivessem dispostos a aceitá-las. Democratizava-se, pela vez primeira, na história educacional da humanidade, o acesso ao saber, que agora não mais se restringia às classes privilegiadas e mais favorecidas. E Nunes, ao afirmar que "todos poderiam ter acesso ao saber", conclui ser este um corolário natural da premissa cristã, de que todos poderiam almejar a salvação.

\section{A Paidéia cristã}

Ao relacionar-se com Deus e nele enraizar sua fé, o homem se questiona diante das grandes questões e significado da vida. Desencadeia-se assim um processo de abertura para o novo, um processo de apreensão de novas verdades, que modelarão novas atitudes, novas aprendizagens. A articulação pedagogia - fé cristã se faz no eixo central da questão do significado de uma vida plena e abundante. A fé: "Eu vim para que tenham vida e a tenham em abundância" (João 10:10). "E a vida eterna é esta: que te conheçam a Ti, o único Deus verdadeiro, e a Jesus Cristo, a quem enviaste" (João 17:3). E 0 conhecimento cristão: "O temor do Senhor é o princípio da sabedoria" (Salmo 111:10). Os apóstolos mesmo receberam uma missão pedagógica: "Ide, pois e ensinai a todas as nações..." (Mateus 28:19) Isto tudo ilustra que:

O ensino foi o elemento vital da igreja cristã primitiva. O mundo helênico, no qual a igreja nasceu, ressaltava orgulhosamente os seus grandes mestres. $\mathrm{O}$ judaísmo, antecedente histórico do cristianismo, era uma religião de mestres. Jesus de Nazaré, através de quem e por causa de quem a igreja foi fundada, era o mestre dos mestres. Tornou-se natural, então, que o ensino devesse, e na realidade assim o fez, ocupar um lugar eminente no ministério da igreja primitiva. (HINSON, s.d, p.19) 
Sabe-se que desde seu início a Igreja nascente envolveu-se com educação. Costume provavelmente herdado do judaísmo, já que na sinagoga lugar de culto, ensinavam-se aos infantis hebreus os preceitos da Toráh: sinagoga - lugar de ensino, e Rabino - professor. Isto já podia ser percebido na cosmovisão judaica, e não por acaso os hebreus são conhecidos como "povo do Livro". "A relação do judeu ortodoxo com o mundo que o cerca não pode ser pensada sem a mediação da Toráh, que assume o papel de uma lente através da qual ele percebe o que comumente chamamos de realidade" (CAON, 1996, p.222). Ao referir-se a lente vem-nos a imagem de um par de óculos conceitual, um paradigma que "filtra" o que pode e deve ser assimilado, e que mais tarde foi adotado pelo cristianismo. Assim

A enorme importância atribuída à Toráh, pelo seu caráter divino, perfeito e eterno, transforma-a no objeto principal de estudo. As outras áreas de conhecimento tendem a ser valoradas e buscadas na medida em que possam auxiliar o indivíduo a melhor compreender ou cumprir a lei divina.

Assim, é através da Toráh que o mundo será conhecido. Tudo está contido nela e o seu estudo não tem limites, nem deve ser interrompido ou concluído. Se por um lado ela não pode ser alterada, pelo outro, deve ser investigada com extremo rigor e ceticismo, e ser submetida a uma análise puramente lógica. Paradoxalmente, a santidade dos livros sempre está presente na mente de quem os estuda, e é como se o processo de questionamento e ratificação se repetisse em cada ieshiváh, em cada geração (CAON, 1996, p.222).

Evidencia-se aqui a função dialética do estudo da Toráh. Indagação/ confirmação, inovação/reprodução, descoberta/recebimento, mímesis/transformação, modelação/autonomia, resultando numa síncrese religiosa, filosófica e pedagógica judaica.

Diferentemente de outros povos do mesmo período, a escola-sinagoga judaica destinava-se a todas as crianças, e não apenas às das classes favorecidas, e igualmente a meninos e meninas, "visto que a lei judaica obrigava todos os pais e todos os povoados a cuidarem da educação das crianças" (SAFRAI, 1999, p.150 negritos acrescentados). Infere-se que tal postura, aberta e de fácil acessibilidade a todos, contribuiu, e muito, para a formação da identidade nacional judaica, e nela é que o cristianismo, recém-surgido, buscou modelo e inspiração para o seu papel educativo, isso contribuiu para que a massa dos recém-conversos, e que formavam a comunidade cristã primitiva, tivesse uma auto-imagem de grupo coeso, unido, com propósitos definidos e distintos. E ainda mais:

Os sábios ensinavam não só nos postos de ensino. Ensinavam onde quer que as pessoas se reunissem e quisessem ouvir suas palavras. Iam de um lugar 
para outro, sozinhos ou acompanhados por um grupo de seus principais alunos; ensinavam nos pátios do Templo de Jerusalém, em casas particulares, no mercado ou nos portões da cidade, nos campos, sob as oliveiras' ou 'sob a figueira'. Nas palavras de tratado Avot lemos: 'Que vossa casa seja um ponto de encontro para os sábios' (Ibid., p.158).

Tal ênfase no estudo e no ensino da Lei e dos Profetas, da Tradição Oral, dos livros sapienciais e dos Salmos, levou Flávio Josefo a afirmar: "Nós os consideramos como divinos, chamamo-los assim; fazemos profissão de observá-los inviolavelmente e morrer com alegria, se for necessário para prová-lo" (JOSEFO, 1974, p. 62). E acrescenta “...trabalhamos principalmente em educar bem nossos filhos, por que nada nos parece tão necessário como instruí-los no conhecimento de nossas santas leis e numa verdadeira piedade que lhes inspira o desejo de as observar" (Ibid., p. 64).

A Paidéia judaica, após a destruição do Segundo Templo, quando cessa toda a ritualística que ali se desenvolvia, passou a enfatizar "que se pode servir melhor a Deus pelo estudo da Toráh - (...) - do que pelos sacrifícios. Daí o papel vital do rabino, do estudioso e especialista da Toráh, cuja interpretação e aplicação à vida foi denominado de judaísmo rabínico" (SZPICZKOWISKI, 2002, p. 36). Aliás, segundo esta mesma autora, tal tendência se apresenta desde os tempos do exílio babilônico, cujo início data de 598-597 a.C.. Dedicação tão forte ao estudo e ao ensino da Toráh tornou-se uma das marcas diferenciadoras dos judeus ortodoxos:

Aprender sem trégua, desde a mais tenra idade até a morte, é dever de cada judeu. Para cumprir com essa obrigação, é importante que ele não se considere infalível ou superior aos outros e, mesmo sendo uma pessoa eminente e importante na sociedade, deve procurar sempre um mestre para instruí-lo. (SZPICZKOWISKI, 2002, p.50).

Percebe-se assim, que para os hebreus sempre houve a preocupação com o estudo da Lei, desde os seus primórdios quando se estabeleceram em Canaã. Com o passar dos séculos tal preocupação acentuou-se.

No centro do currículo da sinagoga e da escola estavam os conceitos de monoteísmo e religião revelada, bem como ênfase em moralidade. Esses conceitos eram inculcados através do estudo de três corpos - Midrash, a exegese das Escrituras; Halakah, o código do judaísmo, precisamente formulado; e Hagga dah, os ensinos não juńdicos das Escrituras, resultantes de estudos mais profundos dos ensinos religiosos, morais e históricos contidos nas Escrituras (HINSON, s.d., p.23). 
Não há exagero ao afirmar-se que o judaísmo apoiava-se e apóia-se nos estudos das Escrituras, da Toráh e do Talmud sem esquecer que

O Antigo Testamento foi a única Bíblia de Jesus e da Igreja primitiva. Como livro da educação judaica, de algum modo, moldou a alma de Jesus. Este assumiu os valores do A.T. como fundamentos do seu evangelho: não veio para 'ab-rogar' a Lei e os profetas, mas 'para cumpri-los'. Cumpri-los era primeiramente levá-los a um ponto de perfeição no qual o sentido primitivo dos textos se superasse a si mesmo, para traduzir em sua plenitude o mistério do Reino de Deus. Cumpri-los era também fazer entrar na experiência humana o conteúdo real das promessas que polarizaram a esperança de Israel. Era desvendar o sentido definitivo de uma história ligada a uma educação espiritual, mostrando sua relação com o ministério da salvação, consumado pela cruz e ressumeição de Jesus" (BÍBLA, 1994; Tradução Ecumênica, Introdução ao Antigo Testamento, p.13-14).

Com o cristianismo a Toráh como que se ampliava para o Novo Testamento e a Bíblia cristã assumia também a sua função formadora, função paidêutica por excelência. E aplica-se à sua totalidade o que era aplicável apenas ao Pentateuco: "ela é a pedagogia de Deus, que constitui um povo para si, moldando-o à sua imagem" (Ibid, p. 20).

Esta preocupação com o estudo e o ensino, tão marcantes da cosmovisão e do modo de ser hebraico, foi agora absorvida pelo cristianismo.

Salvou-se e chegou até nós um escrito datado de fins do século I d.C., portanto, bem próximo dos escritos do Novo Testamento, intitulado "Didaqué - Instrução dos Doze Apóstolos". Tal título nos remete a Atos 2:42: "eles eram assíduos ao ensinamento dos apóstolos...". Eles, no caso, os primeiros conversos, os que acolheram a Palavra e receberam o batismo. A Introdução ao Novo Testamento, da acima citada Bíblia Tradução Ecumênica (1994, p.1836) coloca a Didaqué na categoria de apócrifos, e que devido à estima geral, foi bem conservada, não logrando, contudo, entrar no cânone sagrado. A sua leitura atenta nos permite vislumbrar a comunidade cristã primitiva. Vivia-se dentro de um ambiente estruturalmente pagão. Antepunham-se dois caminhos: o da vida e o da morte, que são apresentados logo na abertura da obra, e suas páginas restantes são de advertência para "não se confundir com o ambiente, de não se deixar manipular por aproveitadores oportunistas (até mesmo disfarçados de profetas), a esperança um pouco nervosa de uma escatologia próxima e o tema da perseverança heróica no caminho da fé..." (DIDAQUÉ, 1989, p. 4-5).

Estavam assim lançados os fundamentos da teologia da educação cristã, sob a ótica messiânica da ressurreição, da ascensão e da expectativa do retorno, e isso se refletia na didaquê (ensino) e no kérygma (pregação). 
Esta evolução paralela e simultânea - teologia e pedagogia cristãs, parece-nos, para usar a expressão de Jeager, estar a serviço "do plano pedagógico da Providência divina" (JAEGER, 1991, p. 54). E ele lembra também o papel central exercido pela Bíblia na Paidéia cristã: "Assim como a Paidéia grega consistia na totalidade do corpo da literatura grega, a Paidéia cristã é a Bíblia" (Ibid., p. 117). E nesta, "a relação professor-aluno permeia todo o texto bíblico, em ambos os Testamentos: no Antigo, Deus é apresentado como educador primeiro, derivando dele a autoridade dos demais educadores; no Novo, Jesus é apresentado como Rabi-Mestre, e seus seguidores como discípulos" (GROSS, 1999, p. 61). Nos Evangelhos encontramos relatos especialmente de três atividades de Cristo: ele pregava, curava e ensinava, com preponderância desta última sobre as demais. E era este Rabi-Mestre, o título mais citado como forma de saudação dirigida a ele. Ele assume nitidamente o seu papel de "educador divino". E Jaeger ressalta, referindo-se à obra Paedagogus escrita por Clemente de Alexandria (séc. II):

A própria escolha do título Paedagogus, que mostra Cristo num novo papel (...) como o "educador da humanidade" (ele) é posto por esse meio em contraste com a idéia grega de cultura no seu todo, pois é esse o sentido exacto que a palavra Paidéia desenvolveu no decurso da sua história. $\mathrm{O}$ emprego da palavra "pedagogo" neste sentido exaltado indica que ela já não significava o escravo que, nos séculos clássicos da Grécia, costumava acompanhar um jovem à escola e desta para casa, mas está mais próxima do sentido filosófico que Platão dava à palavra paidogogein nas Leis, em que define a relação de Deus com o mundo deste modo: "Deus é o pedagogo do mundo inteiro" (JAEGER, 1991, p. 83-84).

E Clemente termina assim a sua obra: "Somos discípulos da celeste Pedagogia!(...) O Logos - Pedagogo criou o mundo e o homem e, através do homem, é doravante, também pedagogo do mundo! (NUNES, 1978, p. 103).

É interessante notar que a Paulo deveria ser conhecida a figura do paidagogós, aquele escravo que não só conduzia as crianças, mas as mantinha disciplinadas. É o que se depreende ao ler Gálatas 3:24: "assim a lei se nos tornou pedagogo encarregado de levar-nos a Cristo...". A pedagogia da Lei dos hebreus agora era apontada como condutora a um novo pedagogo, 0 Mestre, o Raboni, o Cristo.

Estava colocado um novo fundamento para o cristianismo, e o lugar central e fundante antes ocupado pela Toráh, passa a ser ocupado agora por Cristo - "Ele é a pedra que vós, os construtores, tínheis rejeitado e que se tornou a pedra angular" (Atos 4:11). O alicerce agora é Cristo - o Logos - (João 1:1) a Palavra; esta expressão nos remete ao Gênesis, e visa não ao começo do tempo do mundo, mas ao começo absoluto. O Verbo existe de modo surpre- 
endente e eterno" (comentário a João 1:1-3 da Bíblia Tradução Ecumênica, 1994 p. 2044). Para os cristãos o acesso à eternidade consistia em conhecer e entrar em comunhão com Cristo, já que

O Lógos é a imagem perfeita de Deus, segundo a qual tudo se criou. $\mathrm{O}$ universo e, nele o ser humano de maneira toda especial, trazem impressas em si as marcas do Lógos, e subsistem na medida em que nele se afirmam e consistem. (...) Jesus é o próprio Logos feito carne, de tal maneira que, nele, a transcendência de Deus se torna imanência histórica, sem, no entanto anularem-se os extremos: divindade e humanidade (LARA, 1999, p.27).

E é Clemente de Alexandria quem lembra que "nenhuma educação será completa se, ao lado do empenho em cultivar as potências naturais pelo estudo, não se tratar de suscitar e de desenvolver a gnose, o conhecimento das verdades da fé, e a caridade, que é a vida da graça e do amor divino..." (NUNES, 1978, p. 68-69). E mais: "Jesus pôde, então ser apresentado como 0 ideal humano a imitar-se, e o cristianismo como a consumação da Paidéia" (LARA, 1999, p. 27).

\section{Pedagogia do Logos e Paidéia Cristã.}

Diante disso não seria 0 caso de se indagar das relações entre a pedagogia do Logos e a Paidéia cristã? A comparação joananina de Jesus com Logos certamente nos revela as imbricações entre helenismo e judaísmo, que já bastante acentuada nos tempos apostólicos, foram cada vez mais se aprofundando. O pensamento judaico-cristão ao "encarnar" o Logos, fê-lo tomar a face humana de Cristo. A racionalidade divina estava agora ao alcance dos homens. Logos, a verdade eterna, poderia agora dar aos homens 0 acesso à eternidade. A luz de fora da caverna de Platão era o Cristo, que enviado aos homens, mostrou-lhes o caminho para sair de um mundo subterrâneo de trevas. "Eu sou o caminho", "Eu sou a verdade", "Eu sou a luz do mundo", “Eu sou o Alfa e o Omega".

Tal conceituação permitia a fusão entre os pensamentos hebreu e grego e a união do imanente com o transcendente. Logos não era mais só 0 Verbo criador e mantenedor, mas também o redentor, revelador de novas possibilidades a todos os homens - judeus e gentios, gregos ou helenizados. O Logos cristão era um ato de amor, um convite de misericórdia, que convidava a cada um individualmente: "Vinde a mim...".

Ainda estão por serem estudadas as ligações e conexões entre a Paidéia cristã primitiva e os pensadores cristãos, especialmente os não católicos. Estes estudos seriam uma verdadeira "arqueologia" (não no sentido foucaulti- 
ano) da Paidéia cristã primitiva e as inúmeras leituras feitas através dos séculos, e de como estas se prestavam a finalidades ideológicas a serviço das igrejas e religiões. Os próprios pagãos tomavam suas providências para impedir a propagação do estudo e do ensino da nova fé. Ciente da íntima conexão ensino-conversão, em 17 de junho de 362, o imperador Juliano (o Apóstata) excluía os cristãos da função docente, reafirmando decisão anterior de Tertuliano (?155-220) (AVANZINI, 1997, p. 11).

Outra obra cristã primitiva de caráter pedagógico que chegou até nós, (esta do século III), intitulada "Didascália apostólica", ordenava a "proibição completa dos livros diabólicos (sic) e dos pagãos, e não admitia mais que a Bíblia como fonte única de ciência e cultura" (Ibid., p.11). Isto caracterizava um movimento de contracultura que tinha dupla finalidade: manter afastadas as idéias pagãs e preservar a pureza dos ensinos cristãos.

Dentro deste espírito, já a partir do século II a Igreja inicia seu trabalho educativo instituindo o Catecumenato, que em seu apogeu, compreendia três níveis:

- o Catecumenato dos ouvintes, que durava um mínimo de três anos e que preparava para o cristianismo;

- o Catecumenato batismal, durante a quaresma, que explicava os doze artigos do "Símbolo dos Apóstolos" e terminava na noite da Páscoa com o batismo e a confirmação, que eram administradas juntas;

- o Catecumenato mistagógico, durante a semana pascoal, quando o bispo explicava o Pai Nosso e terminava com a comunhão (Ibid., p. 12).

Três anos de estudos precediam o batismo cristão! Isto não só como necessidade de melhor preparar-se, mas também como medida para extirpar qualquer resquício do paganismo. O batismo, como um ritual de iniciação, marcava o início de um novo caminhar, de um viver pautado agora por novos princípios, crenças e valores.

Para Santo Agostinho (354-430) é este o (e não um) itinerário de todo cristão em busca da Verdade. Não uma busca contemplativa, mas essencialmente ativa - transformação pela busca, pela meditação e pela contemplação, enfim, o itinerário platônico linear ascendente.

A verdade deve ser conhecida não simplesmente para saber o que é "O que É"; ela deve ser conhecida para conseguir o repouso completo e a completa tranqüilidade de que a alma necessita. A posse da Verdade, antes de ser objeto de ciência, o é de sapiência ou sabedoria. E a busca da verdade não é um método, mas um "caminho espiritual", uma peregrinação, um itinerário" (MORRA, 2000, p. 60). 
Mas não um caminho já dado, pronto, apenas a indicação de um caminho, e faz-se necessária a disposição do caminhante, mesmo porque é "caminhando que se constroem os caminhos para as caminhadas da libertação" (LEÃO, 2002, p.18). E ele continua - "para caminhar, torna-se indispensável o desprendimento, pois inquieto está o coração do homem em tudo o que tem e é, até chegar a repousar na verdade de Deus" (Ibid., p.18). É este um caminhar paidêutico do "homem espiritual" em direção a Deus, o qual à sua maneira e modo, Agostinho o percorreu por inteiro, e nas suas Confissões ele nos apresenta "o palácio da memória", e dele tira mais um detalhe deste caminho: "Transportei, então, estas forças da minha natureza, subindo por degraus até Aquele que me criou" (SANTO AGOSTINHO, 2002). Outra vez aqui, pela imagem dos degraus, percebe-se o caráter ascendente do itinerário que conduz da apaideuzia à Paidéia cristã. E mais uma vez, é inevitável a comparação com Platão. Não seria o caso de considerar-se Agostinho de 0 mais platônico dos pensadores patrísticos? Não é, certamente, a busca da resposta a esta questão o escopo deste trabalho, mas é uma pergunta que inevitavelmente sempre surge quando se lê Santo Agostinho.

Mas é preciso lembrar que "Agostinho incidia sobre todos os aspectos da vida, preocupado em secundar o papel que a Igreja desempenhava desde o fim da Antiguidade - e continuaria a desempenhar ao longo da Idade Média - como educadora do povo" (LAUAND, 1998, p.12, negrito acrescentado).

Encontramos aqui a Igreja caracterizando uma ação pedagógica educadora do povo - que insere o conhecimento intelectual ao conhecimento salvífico, no que se poderia denominar de "sabedoria da salvação".

De qualquer maneira, foi inevitável, que após um longo processo de maturação, ambas as matrizes - a greao-helênica, e a judaica, acabassem por se fundir numa terceira - a cristã. Dessa forma "a Paidéia cristã vinha, pois, levar à culminância aquilo que a filosofia (Paidéia pagã) já insinuara e iniciara" (LARA, 1999, p. 20).

Paulo, Agostinho, Tomás de Aquino - para citar apenas três exemplos ilustrativos de muitos outros, nos muitos séculos seguintes, devotaram toda a força intelectual do seu pensamento para explorar as múltiplas possibilidades e aplicações deste conceito. O mesmo fizeram Lutero, Melanchton, e Calvino - também citando apenas três, numa outra vertente religiosa, num outro momento histórico. Mas já no século XVI, Comênius (1592-1670), membro da unidade da fé reformada dos Irmãos Morávios, com sua Didática Magna, e a arte de ensinar tudo a todos, mereceu de Abbagnano e Visalberghi (1995, p. 307) o epíteto de "profeta da moderna escola democrática".

Este é todo um contexto pedagógico, que mediante uma multissecular corrente de educadores ligados a esta Paidéia, procuram unir educação e 
as "boas novas" anunciadas por Cristo e seus discípulos. O cristianismo passou a dar aos homens uma nova significação para as suas orientações e um novo centro para os valores morais, individuais e sociais. As escolas catequéticas nas quais o ensino precedia o batismo e a ele dava a admissão, ilustra bem esta união entre ensino, aprendizagem e fé. Aliás, Alcuíno, conselheiro de Carlos Magno, não hesitou em conectar as Sete Artes Liberais com Provérbios 9:1, passagem bíblica que menciona os "sete pilares da sabedoria, reforçando, assim, um caráter espiritual ao aprendizado escolar" (QUEIROZ, 1999, p. 25).

Desta forma, o ensino cristão praticado nas escolas cristãs, sob base cristã, para fundamentar na fé cristã, com evidentes, e muitas vezes exclusivos fins religiosos, mas sempre com conotação paidêutica, acabou por inserir a Paidéia cristã na mente ocidental. Sua missão católica, ou seja, universal, querendo abranger o mundo todo, bem como a todas as pessoas, acabou por contribuir decisivamente para expandir a escolaridade. Sob bases específicas e que lhe são características, mas, que mesmo assim, acabaram por criar as condições necessárias às novas etapas historicamente situadas na evolução das idéias pedagógicas ocidentais.

Manacorda (2002, p. 108) menciona a expressão Paidéia em Cristo, que Giles assim resume:

... 0 processo educativo implica a colaboração mútua entre o mestre terrestre e o Mestre Divino. O mestre terreno ajuda o aluno a estruturar um paradigma mental da verdade etema, e este toma possível o reconhecimento individual e o salto da opinião, ou seja, da representação simbólica à certeza, isto é, à sabedoria, última etapa do conhecimento (GILES, 1987, p.62).

Tem-se, desta forma, um novo paradigma de sabedoria: aquela que emana do divino, o que é lembrado pelo hebreu helenizado Paulo que afirma que "a sabedoria deste mundo é loucura diante de Deus...". (I Coríntios 3:19). E acrescenta que em Deus - Cristo "estão escondidos todos os tesouros da sabedoria e da ciência" (Colossensses 2:3), donde a busca do conhecimento e da sabedoria é progressivamente acessar e participar da sabedoria divina.

A Bíblia de Referência Thompson (1992, p. 1204) faz uma interessante diferenciação entre ambos os conhecimentos - o humano e o divino. Para ele o primeiro tem as seguintes características: conduz à presunção, aumenta a carga da vida, sua busca é exaustiva, promove o orgulho, a vaidade e a tentação. Já o segundo é motivo de regozijo, é obtido pela relação com Deus e a obediência a ele é condição para recebê-lo, liberta a alma de todo o engano e conduz à vida eterna. Para a sabedoria divina ele elenca que ela é constituída pelo temor de Deus, pode ser aumentada, é a aquisição suprema, 
capaz de perceber a verdade divina, e aponta um sólido fundamento, já que tem sua base na Escritura Sagrada. (Ibid, p. 1328)

\section{Considerações finais}

Há que se lembrar que a Paidéia cristã primitiva resultou de uma gradual evolução do conceito grego de Logos (como visto anteriormente), com o conceito neo-testamentário de Filho de Deus. Tal fusão ilustra o fato de que nem os judeus, nem os cristãos primitivos, escaparam da helenização que tomou conta do mundo à época do surgimento do cristianismo, o que acaba por se materializar na Filosofia Medieval. Como diz Jaeger: "Assim, o antigo ideal grego entra numa nova fase de sua vida. A história não se processa a partir de uma definição daquilo que vai buscar ao passado, mas tomando posse de tal e adaptando-o aos seus novos objetivos" (JAEGER, 1991, p. 41).

O Cristianismo alcançará prestígio universal e era "compreendido e explicitado em categorias de pensamento gregas" (JAEGER, 1960, p. 250). Os apologetas, que como o próprio adjetivo indica, não se dirigiam aos já cristãos, mas prioritariamente àqueles que não entendiam (e/ou atacavam) a nova religião, "apelam, não para uma massa inculta e suas representações de deuses, mas para aqueles dentre os seus adversários que possuem uma cultura altamente elevada, especialmente aos reis filósofos de seu tempo, como Adriano e Marco Aurélio" (Ibid, 252-253). Deram, desta forma, a sua contribuição para estabelecer a concordância entre ambas as Paidéias, a grega e a cristã, dando início à apropriação do pensamento platônico pelo cristianismo. Numa fase posterior, a patrística, essa elaboração conceitual, é pormenorizada, dando origem ao sistema teológico cristão.

É assim que "um novo modelo cultural surgiu e floresceu: o da intensa busca intelectual secular realizada num contexto inequivocamente religioso" (MENOCAL, 2004, p. 208). E mais: o judeu Filon e o cristão Agostinho foram precursores, segundo Menocal, no esforço difícil, sistemático e prolongado de "integrar o legado pagão à vida intelectual de uma cultura monoteísta" (Ibid, p. 208).

Gregório de Nissa (ca. 335-após 394) em seus escritos, conforme Jaeger (1960) usa reiteradas vezes da imagem da moldagem para dar a idéia da constituição plástica da forma espiritual e moral no homem, e estabelece um pensamento alicerçador da nova Paidéia - Gênesis. 1:26 - "Deus fez o homem à sua imagem". Portanto, a tarefa da educação cristã é o retorno a esta natureza original perdida, pela via da contemplação e da imitação - imitatio Christi. E este é um processo lento e demorado: aprender a ser e tornar-se cristão é um processo que dura a vida inteira (METTE, 1999, p. 194). 
Na história das idéias filosófico-educacionais, a apresentação cristã do conceito grego de Paidéia permitiu que amplas parcelas da população do mundo de então acessassem o conhecimento que lhes permitia desfrutar de novas oportunidades, quer no âmbito das comunidades cristãs primitivas, quer no meio amplo da sociedade em geral. A modernidade iluminista, na era da Ilustração, continuou este percurso ao defender a idéia de redenção e progresso do homem e da humanidade visa educação pública, leia e gratuita.

Mas estes já eram novos tempos.

\section{Referências}

ABBAGNANO, N.; VISALBERGHI, A. História de la pedagogia. Cidade do México: Fondo de Cultura Econômica, 1995.

AGO STINHO . Confissões. Tradução de J. Oliveira Santos e A. Ambrósio de Pina. Petrópolis: Vozes, 2002.

AVANZINI, Guy. La pedagogía el desde siglo XVII hasta nuestros dias. México: Fondo de Cultura Económica, 1997.

BÍBLIA. Português. De referência Thompson com versículos em cadeia temática. Derfield (Flórida): Vida, 1995.

BÍBLA. Português. Tradução ecumênica. Tradução do Grupo Ecumênico do Brasil. São Paulo,SP: Loyola, 1994.

CAON, Cláudia Malbergier. Quem tem medo da educação religiosa: a educação religiosa ortodoxa judaica. Rio de Janeiro,RJ: Exodus, 1996.

DIDAQUE. 0 catecismo dos primeiros cristãos para as comunidades de hoje. Tradução de Pe. Ivo Storniolo e Euclides Martins Balacin. São Paulo,SP: Paulus, 1989.

DURKHEIM, Emile. A evolução pedagógica. Tradução de Bruno Charles Magne. Porto Alegre: Artes Médicas, 1995.

GIBBON, Edward. Declínio e queda do Império Romano. Tradução Jo sé Paulo Paes. São Paulo,SP: Companhia das Letras, 1989. (Ed. Abreviada).

GILES, Thomas R. História da educação. São Paulo,SP: EPU, 1987.

GRO SS, Janine S. Paulo Freire e Ellen White: encontros e desencontros e os reflexos no ensino superior da Faculdade Adventista de Educação. Dissertação. (Mestrado em Educação) - PUC - PR.. Curitiba, 1999. 
HINSON, E. Glenn. O ensino cristão na igreja primitiva. In: HINSON, E. Glenn; SIEPIERSKI Paulo. Vozes do cristianismo primitivo. São Paulo: Sepal, [19-?]. p.19-34.

JAEGER, Werner. Paidéia Christi. In: Humanistische Reden und Vorträge. Berlin: Walter de Gruyter, 1960.

. Cristianismo primitivo e Paidéia grega. Tradução de Teresa Loureuri Perez. Lisboa: Edições 70, 1991.

JOSEFO, Flávio. Seleções de Flávio Josefo. Tradução de Pe. Vicente Pedroso. São Paulo,SP: Editora das Américas, 1974.

LARA, Tiago Adão. A filosofia nos tempos e contratempos da cristiandade ocidental. Petrópolis: Vozes, 1999.

LAUAND, Luis Jean (org.). Cultura na Idade Média. São Paulo,SP: Martins Fontes, 1998.

LEÃO , Emmanuel Carneiro. As confissões: uma caminhada da libertação. In: SANTO Agostinho. Confissões. Tradução de J. Oliveira Santos e A. Ambrósio Pina. Petrópolis: Vozes, 2002. (Introdução).

MANACORDA, Mário Alighiero. História da educação: da antiguidade aos nossos dias. Tradução de Gaetano Lo Monaco. São Paulo,SP: Cortez, 2002.

MENOCAL, Maria Rosa. $O$ ornamento do mundo. Tradução de Maria Alice Máximo. Rio de Janeiro,RJ: Record, 2004.

METTE, Norbert. Pedagogia da religião. Tradução de Rui Rothe-Neves. Petrópolis: Vozes, 1999.

MORRA, Gianfranco. A religião entre "experiência" e "hermenêutica". In: PENZO, Giorgia; GIBELLINI, Rossino (orgs.). Deus na filosofia do século XX. Tradução de Roberto Leal Pereira. São Paulo,SP: Loyola, 2000.

NUNES, César. A Paidéia cristã. In: . Educar para a emancipação. Florianópolis: Sophos, 2003. p. 79-82.

NUNES, Ruy A. da Costa. História da educação na antiguidade cristã. São Paulo,SP: EPU: Ed. da Universidade de São Paulo, 1978.

QUEIROZ, Tereza Aline Pereira de. Aprender a saber na Idade Média. In: FRIAÇA, Amâncio et al. Trivium e quadrivium: as artes liberais na Idade Média. Cotia, SP: Íbis, 1999. p.9-31. 
SAFRAI, S. Educação elementar: significação religiosa e social no Período Talmúdico. In: UNESCO. Vida e valores do povo judeu. São Paulo,SP: Perspectiva, 1999. p. 149-171.

SANTO AGOSTINHO. Confissões. Petrópolis RJ: Vozes, 2002. p.13-19.

SZPICZKOWSKI, Ana. Educação e Talmude: uma releitura da Ética dos Pais. São Paulo,RJ: Humanitas, FFLCH/USP: Fapesp, 2002.

Recebido: 27 de abril de 2006 Aceito: 28 de julho de 2006 